https://helda.helsinki.fi

\title{
Archaea are prominent members of the prokaryotic communities colonizing common forest mushrooms
}

\section{Rinta-Kanto, J. M.}

2018-10

Rinta-Kanto , J M , Pehkonen , K , Sinkko , H , Tamminen, M V \& Timonen , S 2018 , '

Archaea are prominent members of the prokaryotic communities colonizing common forest

mushrooms ' , Canadian Journal of Microbiology , vol. 64 , no. 10 , pp. 716-726 . https://doi.org/10.1139/cjm-2018-00

http://hdl.handle.net/10138/310518

https://doi.org/10.1139/cjm-2018-0035

unspecified

acceptedVersion

Downloaded from Helda, University of Helsinki institutional repository.

This is an electronic reprint of the original article.

This reprint may differ from the original in pagination and typographic detail.

Please cite the original version. 
1 Archaea are prominent members of the prokaryotic communities colonizing common forest

2 mushrooms

3 Rinta-Kanto $\mathrm{JM}^{1,2 *}$, Pehkonen, $\mathrm{K}^{1}$, Sinkko $\mathrm{H}^{1,3}$, Tamminen $\mathrm{MV}^{4}$, Timonen $\mathrm{S}^{1}$

4

$5 \quad{ }^{1}$ University of Helsinki, Department of Microbiology, Viikinkaari 9, 00014 Helsinki, Finland

$6{ }^{2}$ Current address: Laboratory of Chemistry and Bioengineering, Tampere University of

7 Technology, P.O. Box 541, 33101 Tampere, Finland

$8{ }^{3}$ Current address: University of Helsinki, Faculty of Biological and Environmental Sciences,

$9 \quad$ Viikinkaari 1, 00014 Helsinki, Finland

$10{ }^{4}$ Department of Biology, University Hill, 20014 University of Turku, Finland

$11 *$ Corresponding author: Johanna Rinta-Kanto, Laboratory of Chemistry and Bioengineering,

12 Tampere University of Technology, P.O. Box 541, 33101 Tampere, Finland. Phone: +358-

13 50-447 8332, email: johanna.rinta-kanto@tut.fi 


\section{Abstract}

22 In this study the abundance and composition of prokaryotic communities associated with the

23 inner tissue of fruiting bodies of Suillus bovinus, Boletus pinophilus, Cantharellus cibarius,

24 Agaricus arvensis Lycoperdon perlatum and Piptoporus betulinus were analyzed using

25 culture-independent methods. Our findings indicate that archaea and bacteria colonize the

26 internal tissues of all investigated specimens and that archaea are prominent members of the

27 prokaryotic community. The ratio of archaeal 16S rRNA gene copy numbers to those of

28 bacteria was $>1$ in the fruiting bodies of four out of six fungal species included in the study.

29 The largest proportion of archaeal 16S rRNA gene sequences belonged to thaumarchaeotal

30 classes Terrestrial group and Miscellaneous Crenarchaeotic Group (MCG) and

31 Thermoplasmata. Bacterial communities showed characteristic compositions in each fungal

32 species. Bacterial classes Gammaproteobacteria, Actinobacteria, Bacilli and Clostridia were

33 prominent among communities in fruiting body tissues. Bacterial populations in each fungal

34 species had different characteristics. The results of this study imply that fruiting body tissues

35 are an important habitat for abundant and diverse populations of archaea and bacteria.

38 Keywords: bacteria, archaea, mushroom, qPCR, sequencing 


\section{Introduction}

44 Bacteria colonize the tissues of fruiting bodies of basidiomycetes (Swartz 1929, Danell et al.

45 1993, Dahm et al. 2005, Timonen and Hurek 2006, Pent et al. 2017) and ascomycetes

46 (Barbieri et al. 2007, Quandt et al. 2015). Bacteria and fungi have a partnership throughout

47 the fungal life cycle; bacteria may even be necessary for the formation of fruiting bodies

48 (Cho et al. 2003) and they may supplement the fruiting body with nutrients, such as fixed

49 nitrogen (Barbieri et al. 2010). Association between archaea and ectomycorrhizal fungal

50 hyphae has been observed in boreal forest soil environment (Bomberg et al. 2003, Bomberg

51 and Timonen 2007). Archaea are detected more frequently and their populations are more

52 diverse on tree roots colonized by ectomycorrhizal fungi than on uncolonized roots or humus

53 (Bomberg and Timonen 2009). However, currently there is no information available on

54 whether the association of archaea with fungal hyphae extends from the mycorrhiza to the

55 fruiting bodies of the fungi.

56 Bacteria colonizing the fruiting body tissues of basidiomycetes have been studied mainly

57 using culture-based techniques and microscopy (Li and Castellano 1987, Danell et al. 1993,

58 Dahm et al. 2005, Timonen and Hurek 2006). Recently, Pent et al (2017) performed the first

59 comprehensive study of fruiting body bacteriomes using high throughput sequencing in

60 parallel with culture-based approach. Most of the culturable bacteria recovered from fruiting

61 bodies have been Pseudomonas spp. (Danell et al. 1993, Rangel-Castro et al. 2002, Pent et

62 al. 2017), while other groups, such as Burkholderia (Pent et al. 2017), Paenibacillus

63 (Timonen and Hurek 2006), Xanthomonas spp., Streptomyces spp., Bacillus spp. (Danell et

64 al. 1993) and Azospirillum (Li and Castellano 1987) have been found less consistently.

65 Recent molecular studies have elucidated the internal microbiomes of some ascomycetes

66 indicating that Alphaproteobacteria are predominant members in microbial communities

67 (Barbieri et al. 2007, Barbieri et al. 2010, Antony-Babu et al. 2014, Quandt et al. 2015). 
68 Archaea from temperate environments are notoriously hard to grow in cultures, therefore

69 previous culture-based studies of fruiting body-associated prokaryotes have not been able to

70 touch upon the diversity and abundance of them. Despite the obvious evidence of bacterial

71 colonization of fruiting bodies, not much is known yet about the fruiting body tissue as a

72 habitat for archaea. Quantitative estimates of bacterial abundance have been based on the

73 recovery of culturable bacteria from tissues of fruiting bodies of basidiomycetes. In some

74 cases no or a very low number of culturable bacteria have been recovered (Dahm et al. 2005,

75 Timonen and Hurek 2006).

76 We hypothesized that archaea colonize the internal tissue of the fruiting body, not just

77 mycorrhizas or hyphae in forest soils. The purpose of this study was to quantify and

78 characterize archaeal communities in the internal tissue of fruiting bodies of six different

79 species of common forest mushrooms, using culture-independent techniques, quantitative

80 PCR and 16S rRNA gene sequencing. In parallel, we used the same methods to determine the

81 abundance and community composition bacteria colonizing the internal tissue of fruiting 82 body.

84 Materials and methods

85 Sample collection

86 Sample materials were obtained from fruiting bodies of three species of mychorrhizal fungi:

87 Boletus pinophilus, Suillus bovinus and Cantharellus cibarius and three species of

88 saprophytic fungi: Agrarius arvensis, Lycoperdon perlatum and Piptoporus betulinus. Six

89 specimens of each species were collected. All specimens were young (ca. 4-8 days old) and

90 without larvae. All specimens were collected from southern Finland from locations specified 
91 in Table 1 . After collection, the fruiting bodies were stored at $+4^{\circ} \mathrm{C}$ (1-2 days) until further

92 processing in the laboratory. Fruiting body tissue for DNA-based analysis was collected from

93 the interior of each specimen by first splitting the fruiting body in two halves without

94 touching the exposed tissue and checking for any traces or damage by burrowing animals.

95 Then two flawless, approximately $0.05 \mathrm{~g}$ tissue pieces were cut from the exposed interior at

96 the base of the cap of the fruiting body using a sterile scalpel. The tissue samples were placed

97 in a sterile microcentrifuge tube. Samples were immediately frozen at $-20^{\circ} \mathrm{C}$ until DNA

98 extraction.

DNA extraction

101 Tissue samples were defrosted in room temperature and homogenized in a $1.5 \mathrm{ml}$

102 microcentrifuge tube with sterile glass beads or silicic acid (Sigma Aldrich) and 100-200 $\mu 1$

103 of bead beating buffer solution (Ultra Clean Soil DNA Isolation Kit, MoBio Laboratories)

104 using a sterile acid-washed pestle. DNA was extracted from the homogenized fruiting body

105 tissue with Ultra Clean Soil DNA Isolation Kit (MoBio Laboratories) following the

106 manufacturer's protocol. Two replicate DNA samples originating from the same specimen

107 were pooled before further analyses. Concentration of extracted DNA was determined with

108 Nanodrop spectrophotometer (NanoDrop Spectrophotometer ND-1000, V3.5.2).

110 Quantitative PCR

111 The abundances of bacterial and archaeal 16S rRNA genes in fruiting bodies were

112 determined using quantitative PCR (qPCR). All qPCR reactions were run in triplicate and no-

113 template-control reactions, where DNA template was replaced with an equal volume of 
114 ultrapure water, were run in duplicate. Each $20 \mu \mathrm{l}$ reaction mixture for archaeal 16S rRNA

115 gene quantification consisted of 1x Dynamo Flash SYBR Green mastermix (Thermo), 0.5

$116 \mu \mathrm{M}$ (final concentration) of primers Arch349F 5'-GYGCASCAGKCGMGAAW-3' and

117 539R 5'-GCBGGTDTTACCGCGGCGGCTGRCA-3' (Takai and Horikoshi 2000), $5 \mu$ L of

118 diluted template DNA and nuclease-free water up to $20 \mu \mathrm{L}$. A standard curve was generated

119 using a dilution series of a commercially prepared plasmid consisting of a vector pUC57

120 (length 2710 bp) and a 894 bp insert (GenScript), which was synthetized according to DNA

121 sequence of a $16 \mathrm{~S}$ rRNA gene fragment belonging to an uncultivated 1.1c-group

122 Thaumarchaeota (NCBI accession number $\underline{\text { AM903348.1) }}$. The concentrations of standards

123 ranged from $3 \times 10^{6}$ copies per reaction to $3 \times 10^{2}$ copies per reaction. For eubacterial $16 \mathrm{~S}$

124 rRNA gene quantification, $25 \mu$ l PCR reactions consisted of 1x Maxima SYBR green

125 mastermix (Thermo), $0.3 \mu \mathrm{M}$ (final concentration) of each primer Eub338 5'-

126 ACTCCTACGGGAGGCAGCAG-3' and Eub518 5'-ATTACCGCGGCTGCTGG-3' (Fierer

127 et al. 2005), $5 \mu \mathrm{L}$ of diluted template DNA and ultrapure water up to $25 \mu \mathrm{L}$. Template DNA

128 was substituted with nuclease free water in negative controls. A standard curve was generated

129 using a 10-fold dilution series ranging from $3 \times 10^{6}$ to 30 copies per reaction of a plasmid

130 containing a 16S rRNA gene fragment from Burkholderia glathei. The plasmid was prepared

131 by amplifying a 16S rRNA gene fragment from DNA extracted from a pure culture of

132 Burkholderia glathei by PCR, using primers 25f and 1492R (Hurek et al. 1997) as described

133 above. The fragment was ligated into a pJet 2.1 cloning vector and cloned using GeneJet

134 cloning kit (Thermo Scientific). Plasmid DNA from a culture of transformed cells was

135 purified with GeneJet Plasmid Miniprep Kit (Thermo Scientific) and quantified with

136 Nanodrop spectrophotometer (Thermo Scientific). All qPCR products were verified by melt

137 curve analysis and by running one of the triplicate reactions on an ethidium bromide $(0.2$

$138 \mu \mathrm{g} / \mathrm{ml})$ stained $1.2 \%$ agarose gel. 
Sequencing

141 DNA samples from three specimens of each fungal species were selected for sequencing

142 archaeal and bacterial 16S rRNA gene amplicons. L. perlatum was left out due to an

143 insufficient amount of sequencing template.

144 To prepare the archaeal 16S rRNA gene amplicons for sequencing, the original qPCR

145 products were run on $2 \%$ agarose gel prepared with 1x SB buffer and stained with ethidium

146 bromide $(0.2 \mu \mathrm{g} / \mathrm{ml})$. DNA bands were excised from the gel and purified using GeneJET gel

147 extraction kit (Thermo Scientific). The purified DNA fragments were additionally cleaned

148 using Agencourt AMPure XP magnetic particles (Beckman Coulter) according to the

149 manufacturer's protocol. Sequencing libraries were generated by ligating Illumina flowcell

150 adapters and 9-base barcode sequences using a 2-step protocol adapted from Spencer et al.

151 (2016): adapters were ligated into original PCR products by amplification with

152 miseq_A349_F1 and miseq_A539_R1 primers (Supplementary Table 1). The first ligation

153 PCR reaction consisted of 1x Dynamo Flash SYBR Green mastermix (Thermo), $0.5 \mu \mathrm{M}$ of

154 each primer $\mathrm{F} 1$ and $\mathrm{R} 1,2 \mu \mathrm{L}$ of original PCR product and ultrapure water up to $20 \mu \mathrm{L}$.

155 Thermal cycling was done at $95^{\circ} \mathrm{C}$ for $7 \mathrm{~min} ., 15$ cycles at $95^{\circ} 10 \mathrm{~s} .56^{\circ} 30 \mathrm{~s}$., then $72^{\circ}$ for 5

$156 \mathrm{~min}$. The products with adapters and barcodes were run on a gel, excised, extracted from the

157 gel and purified with Agencourt AMPure XP magnetic particles (Beckman Coulter)

158 following the manufacturer's protocol. The second part of the of the adapters and barcode

159 sequences were ligated in a subsequent PCR reaction, that consisted of 1x Dynamo Flash

160 SYBR Green masterimix (Thermo), $0.25 \mu \mathrm{M}$ of each primer miseq_uni_F2 and

161 miseq_uni_R2_bcxxx (where xxx stands for a code corresponding to a unique 9 nucleotide

162 barcode) (Supplementary Table 1), $2 \mu \mathrm{L}$ of original PCR product and ultrapure water up to 
$16320 \mu \mathrm{L}$. Thermal cycling was done at $95^{\circ} \mathrm{C}$ for $7 \mathrm{~min} ., 8$ cycles at $95^{\circ}$ for $10 \mathrm{~s} .56^{\circ}$ for $30 \mathrm{~s}$,

164 then $72^{\circ}$ for $5 \mathrm{~min}$. PCR products were held at $+4^{\circ} \mathrm{C}$ after completion of thermal cycling. The

165 products were cleaned as described after the first ligation reaction and quantified using Qubit

1662.0 fluorometer (Life Technologies, Thermo Fisher Scientific Inc.). Amplicons were pooled

167 in equimolar quantities into one amplicon library. Sequencing using Illumina MiSeq was

168 done at Macrogen Inc. in Seoul, South Korea.

169 V1 - V3 regions of bacterial 16S rRNA genes were sequenced using Illumina MiSeq at the

170 Institute of Biotechnology at the University of Helsinki. Prior to sequencing, a two-step PCR

171 was used to amplify V1-V3 regions of 16S rRNA genes, using the primers F27 (Chung et al.

172 2004) and pD' (Edwards et al. 1989), amended with partial TruSeq adapter sequences at their

173 5' ends. Sterile water instead of template DNA was added into PCR control samples.

175 Bioinformatics

176 Archaeal 16S rRNA gene sequences were analyzed using QIIME software package, version

177 1.8.0 (Caporaso et al. 2010). Paired-end reads of archaeal 16S rRNA gene amplicons from

178 Illumina MiSeq sequencing were joined with SeqPrep program (URL:

179 https://github.com/jstjohn/SeqPrep). Reads were subsequently quality filtered with

180 split_libraries_fastq.py command using default settings, except that the maximum

181 unacceptable Phred quality score was set at 19. Reads passing quality filtering were clustered

182 into OTUs using pick_open_reference_otus.py workflow command. OTUs were clustered at

$18397 \%$ similarity level. Representative OTU sequences were aligned and checked for presence

184 of chimeras using Chimera Slayer. Taxonomic classification of OTUs was done using

185 BLAST algorithm (Altschul et al. 1990) and Silva database, release 111 as a reference

186 database (Pruesse et al. 2007). 
187 Bacterial 16S rRNA gene sequences were joined using Pear 0.9.10 (Zhang et al. 2014).

188 Reads were subjected to quality filtering and phiX removal using bbduk.sh script provided by

189 BBTools 37.02. The reads were subsequently subjected to the UPARSE pipeline for OTU

190 calling implemented in usearch version 9.2.64 using the standard parameter minsize 2 with

191 the cluster_otu functionality (Edgar 2013). OTU taxonomic classification was performed

192 using assign_taxonomy.py script with standard parameters provided by Qiime version 1.9.1

193 (Caporaso et al. 2010), using Silva database release 128 as a reference database (Quast et al.

194 2013). OTU sequences were aligned using Sina version 1.2.11 (Pruesse et al. 2012) and Silva

195 database release 128 as a reference database. The processed sequence data was normalized

196 using cumulative-sum scaling (CSS) (Paulson et al. 2013) in metagenomeSeq R package

197 (Paulson et al.).

198 An additional analysis was performed for the terrestrial group Thaumarchaeota from this

199 study to investigate their similarity to $1.1 \mathrm{c}$ thaumarchaeotal sequences retrieved from fungal

200 samples by (Bomberg et al. 2010). To investigate the pairwise similarity (\%), the selected

201 sequence fragments from our study were aligned with 16S rRNA gene sequences from 1.1c

202 Thaumarchaeota from the previous study using Geneious software version 6.1.5 (Kearse et

203 al. 2012).

204

205 Statistical analyses

206 Differences in archaeal and bacterial 16S rRNA gene copy abundances determined by qPCR

207 in different fruiting bodies were analyzed using the nonparametric Kruskal-Wallis test, and

208 Wilcoxon signed rank sum test for post hoc comparisons. Tests were performed using the R

209 package Stats (R Core Team 2015), with functions Kruskal.test and wilcox.test for non-

210 paired samples. A regression analysis was used to model the effect of fungal species $(n=6)$ on 
211 the ratio of archaeal to bacterial 16S rRNA gene copies (R). L. perlatum was used as

212 reference group in the analysis. The ratio $\mathrm{R}$ was modelled as: $\mathrm{R}=\beta_{0}+\beta_{\mathrm{i}} \mathrm{X}_{\mathrm{i}}+\varepsilon$, where $\beta_{0}=$

213 reference group, $\mathrm{X}_{1}=A$. arvensis, $\mathrm{X}_{2}=$ B. pinophilus, $\mathrm{X}_{3}=$ C. cibarius, $\mathrm{X}_{4}=P$. betulinus,

$214 \mathrm{X}_{5}=S$. bovinus and $\varepsilon$ is the error term. The model was constructed in R environment using

215 the function $\mathrm{lm}$ in the package Stats (R Core Team 2015). Differences in bacterial

216 communities in the fruiting bodies of fungal species were determined by distance-based

217 Redundancy Analysis (db-RDA) using the function capscale in R package vegan (Oksanen et

218 al. 2017). In the db-RDA, fungal species were used as explanatory variable to constrain the

219 normalized 16S rRNA gene sequence data. The Bray-Curtis dissimilarity index was used to

220 measure between-sample dissimilarity. The significance of differences between bacterial

221 communities in each fungal species was calculated by the function adonis in R package

222 vegan (Oksanen et al. 2017), with 999 permutations.

223

224

Nucleotide sequence accession number

225 Raw sequence data have been deposited to the National Center of Biotechnology

226 Information's Sequence Read Archive under study accession number $\underline{\text { SRP073783. }}$

229 Results

230 Quantities of archaeal and bacterial 16S rRNA gene copies

231 The quantity of archaeal rRNA gene copies ranged from $3.0 \times 10^{6}$ (in L. perlatum) to $3.2 \times 10^{8}$

232 (in S. bovinus) copies per gram (fw) of fruiting body tissue. Copy numbers varied 
significantly between different species (Kruskal-Wallis chi-squared $=22.638, \mathrm{df}=5, \mathrm{p}=$

2340.0004 ) (Figure 1a). Bacterial 16S rRNA gene copy numbers ranged from $5.9 \times 10^{6}$ (in $B$.

235 pinophilus) to $1.9 \times 10^{8}$ copies per gram (in $P$. betulinus). Variations in bacterial copy

236 numbers between species were also significant (Kruskal-Wallis chi-squared $=21.988$, df $=5$,

237 p-value $=0.0005)$ (Figure 1b). Archaeal 16S rRNA gene copy abundance exceeded that of

238 bacterial in all six specimens of $S$. bovinus and B. pinophilus. In C. cibarius, archaeal and

239 bacterial $16 \mathrm{~S}$ copy abundance were roughly equal in half of the specimens (3), while in the

240 other half of the specimens, bacterial 16S rRNA gene copy abundance clearly exceeded

241 archaeal copy abundance (Supplementary Figure 1). Fungal species had a significant effect

242 on the ratio of archaeal to bacterial 16S rRNA gene copy abundance (regression analysis, $\mathrm{p}<$

243 0.001, Supplementary Table 2); in S. bovinus the ratio was is 15.5 times higher and in $B$.

244 pinophilus 22.7 times higher than in L. perlatum, which was chosen as a reference group in

245 the analysis because it had the lowest ratio of 0.4 (Figure 2).

Sequences of archaeal 16 S amplicons

248 Sequencing of PCR amplicons amplified with Archaea-specific primers yielded a total of

24912737 good quality archaeal 16S sequences, which clustered into 57 OTUs at 97\% similarity

250 level. The quality of sequences and thus, sequencing depth varied considerably between samples. Taxonomically classifiable archaeal sequences were distributed in 4-6 archaeal classes depending on the fungal species (Figure 3a). Archaeal communities in fruiting bodies of all fungal species were clearly dominated by thaumarchaeotal classes Terrestrial group,

254 Thermoplasmata, and Miscellaneous Crenarchaeotal Group (MCG) while archaea of Marine

255 group I, Soil Crenarchaeotic group (SCG) and Sc-EA05 Thaumarchaeota represented smaller 256 proportions of the communities. 
257 Sequences classified in this study as Terrestrial group Thaumarchaeota had highest (78-99\%)

258 similarities to $1.1 \mathrm{c}$ thaumarchaeotal sequences, which were retrieved from mycorrhizosphere samples by Bomberg et al. (2010). The highest match ( $99 \%$ identity) to the sequences from

260 our study originated from a pine mycorrhiza. In comparison, Terrestrial group

261 thaumarchaeotal 16S rRNA gene sequences from this study had 63-75\% similarities with

262 representatives of common soil thaumarchaeotal groups: Nitrosotalea devanaterra (group

263 1.1a) and Nitrososphaera viennensis (group 1.1b) (Supplementary Table 3).

264

265

Sequences of bacterial 165 amplicons

266 Sequencing yielded 1647881 sequences that passed quality filtering and they clustered into 177 bacterial OTUs at $97 \%$ similarity level. Bacterial communities of all fungal species formed loose groups showing that they had characteristic bacterial populations. Fungal species explained $30 \%$ of the total variation in the bacterial communities (Figure 4). The populations of fruiting bodies of mycorrhizal fungi did not cluster together apart from those of saprophytic fungi. Bacterial orders with highest relative abundances in the entire data set (Pseudomonadales and Bacillales) were present in all fruiting bodies, but their relative abundances showed considerable variation between fungal species (Figure 3b), and

274 sometimes even between the specimens of the same species. Bacterial community

275 compositions of fruiting bodies of $S$. bovinus differed significantly (adonis, $\mathrm{p}=0.036$ ) from

276 the compositions of other fungal species. Compared to other fruiting bodies, S. bovinus had

277 higher relative abundance of Enterobacteriales, Clostridiales and Dehalococcoidia. Orders

278 Pseudomonadales and Bacillales together formed a major proportion of bacterial

279 communities in A. arvensis (87\%), B. pinophilus (50\%) and P. betulinus (46\%).

280 Lactobacillales were particularly abundant in B. pinophilus, contributing to the high relative 
281 abundance of the class Bacilli in this species, while A. arvensis was heavily dominated by 282 Bacillales. P. betulinus had particularly high proportion of Corynebacteria. In C. cibarius 283 bacterial community had higher relative abundance of Sphingobacteriales (24\%),

284 Rhizobiales (13\%), Caulobacterales (11\%) and Burkholderiales (10\%) than other fungal 285 species.

\section{Discussion}

288

289

290

291

292

293

294

295

296

The results of this study indicate that both archaea and bacteria are abundant in the internal tissues of fruiting bodies, based on enumeration by qPCR. We observed significant variations in the abundance of archaeal and bacterial 16S rRNA gene copies between different fungal species. To our knowledge our data represent the first estimates of archaeal and bacterial abundance in fruiting bodies of fungi obtained using culture-independent approach. The quantities of 16S rRNA gene copies do not correspond to cell numbers as such; according to the ribosomal RNA operon copy number database (rnDB) version 4.4.4 (Stoddard et al. 2015) the number of 16S rRNA gene copies in sequenced archaeal genomes varies from 1 to 4 and 1 to 15 in bacteria. Here, the archaea:bacteria $16 \mathrm{~S}$ rRNA gene copy number ratios $\geq 1$ still indicate that archaea form a significant proportion of prokaryotic biomass in fruiting body tissues of some fungi. Such high ratios of archaeal versus bacterial 16S rRNA gene copy abundances are not common in terrestrial habitats, although in archaea-rich marine sediments archaeal abundances exceeding that of bacteria have been observed (Lipp et al. 2008, Lloyd et al. 2013). In contrast to previous culture-based studies, our new data show that bacteria are abundant in the internal tissues of fruiting bodies, such as in S. bovinus, where the numbers of culturable bacteria were very low (Timonen and Hurek 2006). 
304 This study shows that archaeal communities in fruiting body tissues are diverse based on 305 sequencing of $16 \mathrm{~S}$ rRNA genes. Fruiting bodies included in this study were colonized by 306 archaeal classes that are commonly found in both aquatic and terrestrial environments. The 307 metabolic potential and roles of these organisms in the prokaryotic community inside the

308 fruiting bodies remains unknown at this point due to lack of cultured representatives or

309 genomic information. A metagenomic assembly of representatives from the "Soil

310 Crenarchaeotic Group" (SCG) suggested, that these archaea might participate in both

311 nitrification and denitrification (Butterfield et al. 2016). Some of the dominant groups, such 312 as the ubiquitous MCG group, are diverse both phylogenetically and metabolically (Kubo et 313 al. 2012, Meng et al. 2014). In marine sediments the MCG group archaea may derive energy 314 from mineralization of proteins (Lloyd et al. 2013), degradation of aromatic compounds 315 (Meng et al. 2014), and possibly also from physically and chemically recalcitrant organic 316 matter, such as membrane lipids (Takano 2010). Marine group I thaumarchaeota are mostly 317 pelagic mixotrophs also with versatile metabolic potential, including aerobic ammonia 318 oxidation and hydrolysis of urea (Swan et al. 2014). Thermoplasmata were the only 319 euryarchaeal class present in the fruiting bodies. Sequences belonging to archaea of this class 320 (order Thermoplasmatales) have been recovered from forest soil (Burke et al. 2012) as well 321 as from freshwater habitats (Jurgens et al. 2000, Fillol et al. 2015). Thermoplasmatales may 322 have methanogenic potential (Paul et al. 2012), but their activities are still mostly unknown.

323 In this study, sequencing depth within replicates of same species as well as between different 324 specimens varied considerably and this also likely affected strongly the observed numbers of 325 archaeal OTUs. For this reason statistical assessment of differences between archaeal communities was not performed, as the results would not represent accurately the natural

327 variation between the communities. 
328 Although our results give the first glimpse of the diversity of archaea colonizing internal 329 tissues of fruiting bodies, the short length $(<200 \mathrm{bp})$ of the $16 \mathrm{~S}$ rRNA gene fragments set

330 limits to taxonomic resolution and comparisons with uncultivated archaea found in specific

331 habitats. Nevertheless, the short 16S rRNA gene sequences of the terrestrial group

332 Thaumarchaeota from this study had high \% identities with sections of longer sequences of

333 mycorrhizosphere associated 1.1c Thaumarchaeota previously found by Bomberg et al.

334 (2003, 2010). This implies that archaea from mycorrhizal roots and external hyphae might

335 effectively colonize the fruiting bodies as well. It has been hypothesized previously that the

336 group 1.1c Thaumarchaeota are involved in carbon cycling through uptake and turnover of

337 single-carbon compounds (such as methane, methanol or carbon dioxide) and they may carry

338 out this role also in fruiting bodies as well (Timonen and Bomberg 2009, Bomberg et al.

339 2010).

340 Bacterial communities between different fungal species showed species-specific

341 characteristics, although only the bacterial community of S. bovinus was statistically

342 significantly different from the others in this study. Fungal genus was a significant factor

343 affecting the composition of bacterial community in a study comprising fruiting bodies of

344 eight genera within the class Agaricomycetes (Pent et al. 2017). There were large variations

345 in relative abundances of certain bacterial taxa within biological replicates, such as in the

346 case of Corynebacteriales. Because of this, we have focused the discussion of the results on

347 bacterial groups that appeared evenly in biological replicates to avoid spurious conclusions.

348 The variation between biological replicates may be caused by uneven distribution of bacteria

349 within the fungal tissue or variation between individual fruiting bodies. Soil properties may

350 also have an effect on the composition of bacterial community in fruiting body tissue (Pent $e t$

351 al. 2017). In this study replicates for each species originated from the same general area and

352 therefore there should be no major differences in soil properties that could have an effect on 
the composition of bacterial communities, although we can not exclude the possible effect of

354 minor differences within the sampling locations.

355 Class Enterobacteriaceae (orders Pseudomonadales and Enterobacteriales) was a predominant bacterial group in all fruiting bodies. They were also predominant groups among bacteria recovered through cultivation from fruiting bodies of $C$. cibarius and $S$. bovinus by Pent et al (2017). Enterobacteria and Pseudomonads can act as mycorrhiza helper bacteria facilitating interaction between plant roots and mycorrhizal fungi (Frey-Klett et al. 2007). In this study, we also found a high relative abundance of Bacilli in fruiting bodies of $A$. arvensis, $P$. betulinus and B. pinophilus, whereas they formed only $<2 \%$ of the community in C. cibarius and S. bovinus. Bacilli have been recovered from inner tissues of fruiting bodies through cultivation (Danell et al. 1993, Zagriadskaia et al. 2014). In line with our findings, Pent et al. (2017) found a low relative abundance of Bacilli in S. bovinus and none in C. cibarius by sequencing bacterial 16S rRNA genes. Orders Clostridiales and and Dehalococcoides had particularly high relative abundances in S. bovinus. There are no previous reports of finding Dehalococcoides in fungal fruiting bodies while Pent et al. (2017) had detected Clostridiales in some of their fruiting body material. Clostridiales are obligate anaerobes and their role may be related to cellulose degradation (de Boer et al. 2005). Dehalococcoides are obligate organohalide respiring bacteria (Loffler et al. 2013) and their presence is likely linked to degradation of organohalogens produced by the host. Basidiomycetes fungi are capable of $d e$ novo synthesis of halogenated organic compounds making them a major source of organohalogens in terrestrial environments (deJong and Field 1997). In our study, C. cibarius had higher relative abundance of Sphingobacteriales than in other fungal species. Pent et al. (2017) found sequences of these bacteria from $C$. cibarius tissue, but were not able to culture them, which may explain why these bacteria have not been recovered from fruiting body tissues by cultivation in earlier culture-based studies. Also Alphaproteobacterial orders 
Rhizobia and Caulobacteria and Betaproteobacterial order Burkholderiales had higher relative abundances in C. cibarius than in other fruiting bodies. Alphaproteobacteria were prominent groups in ascomycete Elaphomyces granulatus based on relative abundance of 16S rRNA gene sequences (Quandt et al. 2015). Rhizobia and Burkholderiales were also found in bacterial 16S rRNA gene sequence libraries from C. cibarius and S. bovinus in the study by Pent et al. (2017). To our knowledge, Caulobacteria have not been detected by sequencing or cultivation in fruiting bodies yet. These three orders may have a role in glucan degradation, as suggested by Eichorst and Kuske (2012). Bacteria belonging to these classes are adapted in low-nutrient environments and they may have a role in supplementing nutritional demands of the host by fixing nitrogen, (Li and Castellano 1987, Barbieri et al. 2010, Sellstedt and Richau 2013), or solubilizing phosphate for the use of the fungus (Pavic et al. 2013).

The internal environment in fruiting bodies reshapes the bacterial communities compared to communities found e.g. in Pinus sylvestris mycosphere and in the surrounding uncolonized soil. These environments are dominated by bacteria belonging to classes Alphaproteobacteria, Actinobacteria and Acidobacteria (Timonen et al. 2017). Factors affecting the composition of the prokaryotic community in the fruiting body tissue include the presence of antimicrobial compounds excreted by the fungi (de Carvalho et al. 2015). Also carbohydrate, crude protein, sugar and lipid contents between Boletus edulis, A. arvensis, C. cibarius and L. perlatum can vary greatly (Barros et al. 2007, Barros et al. 2008, Kalac 2009, Heleno et al. 2011), which could be a selecting factor for prokaryotic community composition. The availability of different carbon sources inside the fruiting bodies as well as the ability of colonizing prokaryotes to utilize the fungal storage sugars (such as trehalose and mannitol) could explain at least some proportion of the variation seen in prokaryotic community compositions. Also, the physical composition of the fruiting body, such as 
403 porosity and moisture, may play a role in shaping the prokaryotic abundance and community 404 composition and distribution within the fruiting body. It is likely that the increased moisture 405 of degrading fruiting bodies with larval infestation and increased leakage of substrates from 406 fungal tissues could support more bacteria than young fruiting bodies. All fruiting bodies 407 analyzed in this study were relatively young and showed no signs of decay. However, even 408 small variations in fruiting body age may cause differences in the archaeal and bacterial $16 \mathrm{~S}$ copy abundances and community composition as the biochemical composition of the fruiting body tissue changes over time (Citterio et al. 2001, Barbieri et al. 2010).

411 The view of archaeal biomass in ecosystems and their contribution to biogeochemical cycles

412 has changed radically in recent years - however, our understanding of their distribution in

413 different habitats is still developing. The mixture of both aquatic and terrestrial archaeal

414 classes in the communities colonizing the tissues of fruiting bodies suggests that present

415 habitat-based broad classification will likely be subject to change in the future, as archaeal

416 diversity in different habitats is further explored. The data from this study do not explain the

417 success of archaea in fruiting body tissues. The apparent enrichment of archaea in fruiting 418 body tissues of $B$. pinophilus and S. bovinus suggests that fungi-archaea associations must be 419 important in ecosystems to the extent that archaea remain associated with the fungi even 420 outside the soil environment to accompany fruiting bodies during their short life cycle 421 (approximately 2 weeks). It is not yet known whether the composition of the archaeal population changes over the life cycle of the host and whether the archaeal activity affects the host somehow. Such an abundance of archaea in this (or any) natural habitat shows that the

424 environment is important in shaping the composition of the microbial community associated

425 with it. Differences in bacterial abundance and in community composition between different

426 fungal species suggest that bacterial populations form a network of interactions between 427 themselves and the host. The composition of the community is likely a result of protagonistic 
and antagonistic interactions between the host and microbes as well as between the microbes themselves. A recent study by Schulz-Bohm et al. demonstrated the pervasive effect of microbes to a life style of a saprotrophic fungus Mucor hiemalis (Schulz-Bohm et al. 2017).

431 An antibiotic-induced shift in microbial community composition altered the morphology,

432 secondary metabolite production and morphology of the fungus. These results suggest that

433 the network of interactions between fungi and bacteria may be more complex than is

434 previously thought and bacteria are important cohabitants for fungi.

435 Our findings transform our view of prokaryotic populations in fruiting bodies. We identify 436 fruiting bodies as a previously unknown habitat for temperate archaeal populations, where in some cases archaeal abundance may exceed that of bacteria. We also show that fruiting bodies of different fungal species harbor characteristic bacterial communities.

443 This work was funded by Finnish Academy grant no. 131819. We would also like to

444 acknowledge Sarah Preheim for designing and generously providing the adapter and barcode

445 sequences for our use in Illumina sequencing and Daniel Piotrowski for proofreading the 446 manuscript. 
452 Altschul S.F., Gish W., Miller W., Myers E.W., and Lipman D.J. 1990. Basic local alignment

453 search tool. Journal of Molecular Biology 215: 403-410.

454 Antony-Babu S., Deveau A., Van Nostrand J.D., et al. 2014. Black truffle-associated

455 bacterial communities during the development and maturation of Tuber melanosporum

456 ascocarps and putative functional roles. Environmental Microbiology 16: 2831-2847.

457 Barbieri E., Guidi C., Bertaux J., et al. 2007. Occurrence and diversity of bacterial

458 communities in Tuber magnatum during truffle maturation. Environmental Microbiology 9:

459 2234-2246.

460 Barbieri E., Ceccaroli P., Saltarelli R., et al. 2010. New evidence for nitrogen fixation within

461 the Italian white truffle Tuber magnatum. Fungal Biology 114: 936-942.

462 Barros L., Ventuizini B.A., Baptista P., Estevinho L.M., and Ferreira I.C.F.R. 2008 Chemical 463 composition and biological properties of Portuguese wild mushrooms: A comprehensive 464 study. Journal of Agricultural and Food Chemistry 56: 3856-3862.

465 Barros L., Baptista P., Correia D.M., Casal S., Oliveira B. and Ferreira I.C.F.R. 2007 Fatty

466 acid and sugar compositions, and nutritional value of five wild edible mushrooms from

467 Northeast Portugal. Food Chemistry 105: 140-145.

468 Bomberg M. and Timonen S. 2007. Distribution of Cren- and Euryarchaeota in Scots pine 469 mycorrhizospheres and boreal forest humus. Microbial Ecology 54: 406-416.

470 Bomberg M. and Timonen S. 2009 Effect of tree species and mycorrhizal colonization on the 471 archaeal population of boreal forest rhizospheres. Applied and Environmental Microbiology $472 \quad$ 75: $308-315$. 
473 Bomberg M., Jurgens G., Saano A., Sen R. and Timonen S. 2003. Nested PCR detection of

474 Archaea in defined compartments of pine mycorrhizospheres developed in boreal forest

475 humus microcosms. FEMS Microbiology Ecology 43: 163-171.

476 Bomberg M., Montonen L. and Timonen S. 2010. Anaerobic Eury- and Crenarchaeota

477 inhabit ectomycorrhizas of boreal forest Scots pine. European Journal of Soil Biology 46:

$478 \quad 356-364$.

479 Burke D.J., Smemo K.A., Lopez-Gutierrez J.C. and DeForest J.L. 2012. Soil fungi influence 480 the distribution of microbial functional groups that mediate forest greenhouse gas emissions.

481 Soil Biology and Biochemistry 53: 112-119.

482 Butterfield C.N., Li Z., Andeer P.F., et al. 2016. Proteogenomic analyses indicate bacterial 483 methylotrophy and archaeal heterotrophy are prevalent below the grass root zone. Peerj 4.

484 Caporaso J.G., Bittinger K., Bushman F.D., DeSantis T.Z., Andersen G.L. and Knight R. 485 2010. PyNAST: a flexible tool for aligning sequences to a template alignment.

486 Bioinformatics 26: 266-267.

487 Caporaso J.G., Kuczynski J., Stombaugh J., et al. 2010. QIIME allows analysis of high488 throughput community sequencing data. Nature Methods 7: 335-336.

489 Cho Y.S., Kim J.S., Crowley D.E. and Cho B.G. 2003. Growth promotion of the edible 490 fungus Pleurotus ostreatus by fluorescent pseudomonads. FEMS Microbiology Letters 218: $491 \quad 271-276$.

492 Chung J., Ha E.S., Park H.R. and Kim S. 2004. Isolation and characterization of 493 Lactobacillus species inhibiting the formation of Streptococcus mutans biofilm. Oral 494 Microbiology and Immunology 19: 214-216. 
495 Citterio B., Malatesta M., Battistelli S., et al. 2001. Possible involvement of Pseudomonas

496 fluorescens and Bacillaceae in structural modifications of Tuber borchii fruit bodies.

497 Canadian Journal of Microbiology 47: 264-268.

498 Dahm H., Wrótniak W., Strzelczyk E., Li C.-Y. and Bednarska E. 2005. Diversity of

499 culturable bacteria associated with fruiting bodies of ectomycorrhizal fungi. Phytopathologia

$500 \quad$ Polonica 38: 51-62.

501 Danell E., Alstrom S. and Ternstrom A. 1993. Pseudomonas fluorescens in association with 502 fruit bodies of the ectomycorrhizal mushroom Cantharellus cibarius. Mycological Research 503 97: 1148-1152.

504 de Boer W., Folman L.B., Summerbell R.C. and Boddy L. 2005. Living in a fungal world: 505 impact of fungi on soil bacterial niche development. FEMS Microbiology Reviews 29: 795506811.

507 de Carvalho M.P., Turck P. and Abraham W.R. 2015. Secondary metabolites control the 508 associated bacterial communities of saprophytic basidiomycotina fungi. Microbes and 509 Environments 30: 196-198.

510 deJong E. and Field J.A. 1997. Sulfur tuft and turkey tail: Biosynthesis and biodegradation of 511 organohalogens by basidiomycetes. Annual Review of Microbiology 51: 375-414.

512 Edgar R.C. 2013. UPARSE: highly accurate OTU sequences from microbial amplicon reads.

$513 \quad$ Nature Methods 10: 996-998.

514 Edwards U., Rogall T., Blocker H., Emde M. and Bottger E.C. 1989. Isolation and direct 515 complete nucleotide determination of entire genes - Characterization of a gene coding for 516 16S ribosomal RNA Nucleic Acids Research 17: 7843-7853. 
517 Eichorst S.A. and Kuske C.R. 2012. Identification of cellulose-responsive bacterial and

518 fungal communities in geographically and edaphically different soils by using stable isotope

519 probing. Applied and Environmental Microbiology 78: 2316-2327.

520 Fierer N., Jackson J.A., Vilgalys R. and Jackson R.B. 2005. Assessment of soil microbial

521 community structure by use of taxon-specific quantitative PCR assays. Applied and

522 Environmental Microbiology 71: 4117-4120.

523 Fillol M., Sanchez-Melsio A., Gich F. and Borrego C.M. 2015. Diversity of Miscellaneous

524 Crenarchaeotic Group archaea in freshwater karstic lakes and their segregation between

525 planktonic and sediment habitats. FEMS microbiology ecology 91.

526 Frey-Klett P., Garbaye J. and Tarkka M. 2007. The mycorrhiza helper bacteria revisited. New

527 Phytologist 176: 22-36.

528 Heleno S.A. Barros L., Sousa M.J., Martins A., Santos-Buelga C. and Ferreira I.C.F.R. 2011.

529 Targeted metabolites analysis in wild Boletus species. Lwt-Food Science and Technology 44:

$530 \quad 1343-1348$.

531 Jurgens G., Glöckner F.-O., Amann R., Saano A., Montonen L., Likolammi M. and Münster

532 U. 2000. Identification of novel Archaea in bacterioplankton of a boreal forest lake by

533 phylogenetic analysis and fluorescent in situ hybridization. FEMS Microbiology Ecology 34:

$534 \quad 45-56$.

535 Kalac P. 2009. Chemical composition and nutritional value of European species of wild 536 growing mushrooms: A review. Food Chemistry 113: 9-16.

537 Kearse M., Moir R., Wilson A., et al. 2012. Geneious Basic: An integrated and extendable

538 desktop software platform for the organization and analysis of sequence data. Bioinformatics

539 28: 1647-1649. 
540 Kubo K., Lloyd K.G., Biddle J.F., Amann R., Teske A. and Knittel K. 2012. Archaea of the

541 Miscellaneous Crenarchaeotal Group are abundant, diverse and widespread in marine

542 sediments. ISME Journal 6: 1949-1965.

543 Li C.Y. and Castellano M.A. 1987. Azospirillum isolated from within sporocarps of the

544 mycorrhizal fungi Hebeloma crustuliniforme, Laccaria laccata and Rhizopogon vinicolor.

545 Transactions of the British Mycological Society 88: 563-565.

546 Lipp J.S., Morono Y., Inagaki F. and Hinrichs K.-U. 2008). Significant contribution of

547 Archaea to extant biomass in marine subsurface sediments. Nature 454: 991-994.

548 Lloyd K.G., May M.K., Kevorkian R.T. and Steen A.D. 2013. Meta-analysis of

549 quantification methods shows that archaea and bacteria have similar abundances in the

550 subseafloor. Applied and Environmental Microbiology 79: 7790-7799.

551 Lloyd K.G., Schreiber L., Petersen D.G., et al. (2013) Predominant archaea in marine

552 sediments degrade detrital proteins. Nature 496: 215-218.

553 Loffler F.E., Yan J., Ritalahti K.M., et al. 2013. Dehalococcoides mccartyi gen. nov., sp nov.,

554 obligately organohalide-respiring anaerobic bacteria relevant to halogen cycling and

555 bioremediation, belong to a novel bacterial class, Dehalococcoidia classis nov., order

556 Dehalococcoidales ord. nov and family Dehalococcoidaceae fam. nov., within the phylum

557 Chloroflexi. International Journal of Systematic and Evolutionary Microbiology 63: 625-635.

558 Meng J., Xu J., Qin D., He Y., Xiao X. and Wang F. (2014) Genetic and functional properties

559 of uncultivated MCG archaea assessed by metagenome and gene expression analyses. The

$560 \quad$ ISME Journal 650-659.

561 Oksanen J., Blanchet F., Friendly M., et al. 2017. vegan: Community Ecology Package. R

562 package version 2.4-2. https://CRAN.R-project.org/package=vegan. 
563 Paul K., Nonoh J.O., Mikulski L. and Brune A. 2012. "Methanoplasmatales,"

564 Thermoplasmatales-related Archaea in termite guts and other environments, are the seventh

565 order of methanogens. Applied and Environmental Microbiology 78: 8245-8253.

566 Paulson J., Talukder H., Pop M. and Bravo H. metagenomeSeq: Statistical analysis for sparse

567 high-throughput sequencing. Bioconductor package: 1.16.0.

568 http://cbcb.umd.edu/software/metagenomeSeq.

569 Paulson J.N., Stine O.C., Bravo H.C. and Pop M. 2013. Differential abundance analysis for 570 microbial marker-gene surveys. Nature Methods 10: 1200-1202.

571 Pavic A., Stankovic S., Saljnikov E., Kruger D., Buscot F., Tarkka M. and Marjanovic Z.

572 2013. Actinobacteria may influence white truffle (Tuber magnatum Pico) nutrition, ascocarp

573 degradation and interactions with other soil fungi. Fungal Ecology 6: 527-538.

574 Pent M., Poldmaa K. and Bahram M. 2017. Bacterial Communities in Boreal Forest

575 Mushrooms Are Shaped Both by Soil Parameters and Host Identity. Frontiers in 576 Microbiology 8.

577 Pruesse E., Peplies J. and Glöckner F.O. 2012. SINA: Accurate high-throughput multiple 578 sequence alignment of ribosomal RNA genes. Bioinformatics 28: 1823-1829.

579 Pruesse E., Quast C., Knittel K., Fuchs B.M., Ludwig W., Peplies J. and Glöckner F.O. 2007. 580 SILVA: a comprehensive online resource for quality checked and aligned ribosomal RNA 581 sequence data compatible with ARB. Nucleic Acids Research 35: 7188-7196.

582 Quandt C.A., Kohler A., Hesse C.N., Sharpton T.J., Martin F. and Spatafora J.W. 2015.

583 Metagenome sequence of Elaphomyces granulatus from sporocarp tissue reveals

584 Ascomycota ectomycorrhizal fingerprints of genome expansion and a Proteobacteria-rich

585 microbiome. Environmental Microbiology 17: 2952-2968. 
586 Quast C., Pruesse E., Yilmaz P., et al. 2013. The SILVA ribosomal RNA gene database

587 project: improved data processing and web-based tools. Nucleic Acids Research 41: D590-

588 D596.

589 R Core Team. 2015. R: A Language and Environment for Statistical Computing. R

590 Foundation for Statistical Computing, Vienna, Austria.

591 Rangel-Castro J.I., Levenfors J.J. and Danell E. 2002. Physiological and genetic

592 characterization of fluorescent Pseudomonas associated with Cantharellus cibarius. Canadian 593 Journal of Microbiology 48: 739-748.

594 Schulz-Bohm K., Tyc O., de Boer W., et al. 2017. Fungus-associated bacteriome in charge of 595 their host behavior. Fungal Genetics and Biology 102: 38-48.

596 Sellstedt A. and Richau K.H. 2013. Aspects of nitrogen-fixing Actinobacteria, in particular 597 free-living and symbiotic Frankia. FEMS Microbiology Letters 342: 179-186.

598 Stoddard S.F., Smith B.J., Hein R., Roller B.R.K. and Schmidt T.M. 2015. rrnDB: improved 599 tools for interpreting rRNA gene abundance in bacteria and archaea and a new foundation for 600 future development. Nucleic Acids Research 43: D593-D598.

601 Swan B.K., Chaffin M.D., Martinez-Garcia M., et al. 2014. Genomic and Metabolic

602 Diversity of Marine Group I Thaumarchaeota in the Mesopelagic of Two Subtropical Gyres. 603 PLOS ONE 9: e95380.

604 Swartz D. 1929. Bacteria in puffballs. Michigan Academy of Science, Arts and Letters 11: $605 \quad 285-296$.

606 Takai K. and Horikoshi K. 2000. Rapid detection and quantification of members of the

607 archaeal community by quantitative PCR using fluorogenic probes. Applied and

608 Environmental Microbiology 66: 5066-5072. 
609 Takano Y.C., Chikaraishi Y., Ogawa N.O., Nomaki H., Morono Y., Inagaki F., Kitazato H.,

610 Hinrichs K.-U., Ohkouchi N. 2010 Sedimentary membrane lipids recycled by deep-sea

611 benthic archaea. Nature Geoscience 3: 858-861.

612 Timonen S. and Bomberg M. 2009. Archaea in dry soil environments. Phytochemistry

613 reviews 8 : 505-518.

614 Timonen S. and Hurek T. 2006. Characterization of culturable bacterial populations

615 associating with Pinus sylvestris - Suillus bovinus mycorrhizospheres. Canadian Journal of

616 Microbiology 52: 769-778.

617 Timonen S., Sinkko H., Sun H., Sietio O.M., Rinta-Kanto J.M., Kiheri H. and Heinonsalo J.

618 2017. Ericoid Roots and Mycospheres Govern Plant-Specific Bacterial Communities in

619 Boreal Forest Humus. Microbial Ecology 73: 939-953.

620 Zagriadskaia Y.A., Lysak L.V., Sidorova I.I., Aleksandrova A.V. and Voronina E.Y. 2014.

621 Bacterial complexes of the fruiting bodies and hyphosphere of certain basidiomycetes.

622 Biology Bulletin 41: 12-18.

623 Zhang J., Kobert K., Flouri T. and Stamatakis A. 2014. PEAR: a fast and accurate Illumina

624 Paired-End reAd mergeR. Bioinformatics 30: 614-620.

625

626

627

628

629

630

631 
633

634 Table 1. Fungal species included in the study and characterization of sample collection sites located in 635 Southern Finland.

636

\begin{tabular}{|c|c|c|c|}
\hline Species & $\begin{array}{l}\text { Sample } \\
\text { code }\end{array}$ & $\begin{array}{l}\text { Coordinates of sample } \\
\text { collection sites }\end{array}$ & $\begin{array}{l}\text { Site characteristics (no. of } \\
\text { specimens collected) }\end{array}$ \\
\hline $\begin{array}{l}\text { Suillus bovinus (Fr.) } \\
\text { Roussel }\end{array}$ & $\mathrm{Sb}$ & $60^{\circ} 01^{\prime} \mathrm{N}, 23^{\circ} 34^{\prime} \mathrm{E}$ & Dry pine forest (6). \\
\hline $\begin{array}{l}\text { Boletus pinophilus Pilát \& } \\
\text { Dermek (Bp) }\end{array}$ & $\mathrm{Bp}$ & $\begin{array}{l}60^{\circ} 38^{\prime} \mathrm{N}, 25^{\circ} 20^{\prime} \mathrm{E}, \\
59^{\circ} 54^{\prime} \mathrm{N}, 23^{\circ} 43^{\prime} \mathrm{E}\end{array}$ & $\begin{array}{l}\text { Dry pine forest (5), mixed } \\
\text { forest (1) }\end{array}$ \\
\hline Cantharellus cibarius Fr. & $\mathrm{Cc}$ & $\begin{array}{l}60^{\circ} 01^{\prime} \mathrm{N}, 23^{\circ} 34^{\prime} \mathrm{E} \\
59^{\circ} 54^{\prime} \mathrm{N}, 23^{\circ} 43^{\prime} \mathrm{E},\end{array}$ & $\begin{array}{l}\text { Dry pine forest (2), mixed } \\
\text { forest (4) }\end{array}$ \\
\hline Agaricus arvensis Schaeff. & Aa & $60^{\circ} 11^{\prime} \mathrm{N}, 24^{\circ} 53^{\prime} \mathrm{E}$ & Grassy field (6) \\
\hline Lycoperdon perlatum Pers. & $\mathrm{Lp}$ & $60^{\circ} 13^{\prime} \mathrm{N}, 25^{\circ} 01^{\prime} \mathrm{E}$ & Mixed forest (6) \\
\hline $\begin{array}{l}\text { Piptoporus betulinus } \\
\text { (Bull.) P. Karst. }\end{array}$ & $\mathrm{Pb}$ & $59^{\circ} 54^{\prime} \mathrm{N}, 23^{\circ} 43^{\prime} \mathrm{E}$ & Mixed forest (6) \\
\hline
\end{tabular}

637

638

639

640

641

642 Figure captions

643

644 Figure 1. Abundance of archaeal (A) and bacterial (B) 16S rRNA gene sequences in fruiting

645 bodies. Solid bars represent means ( $n=6$, except for $L p n=3$ ), and error bars standard errors. 
646 Different letter above the bar indicates statistically significant difference (Wilcoxon signed

647 rank sum test, $\mathrm{p}<0.05)$.

648

649 Figure 2. Ratio of archaeal to bacterial 16S rRNA gene copy abundance. The copy numbers

650 were determined using qPCR with domain-specific primers. Regression analysis determined

651 that S. bovinus and B. pinophilus (marked with an asterisk) have statistically significant (p <

652 0.001), increasing effect on the ratio of archaeal to bacterial 16S rRNA gene copy numbers.

653 Dashed line indicates a ratio of 1:1.

654

655 Figure 3. Taxonomic distribution of archaeal (A) and bacterial (B) 16S sequences in different

656 fungal species. Relative abundances are calculated from pooled sequences of three biological

657 replicate samples.

658

659 Figure 4. Distance-based Redundancy Analysis (db-RDA) of bacterial populations in fruiting

660 body tissues. The ordination is based on Bray-Curtis dissimilarity using fungal groups as

661 explanatory variables. The ellipses represent variation around the group centroids at 0.75

662 confidence interval.

663 

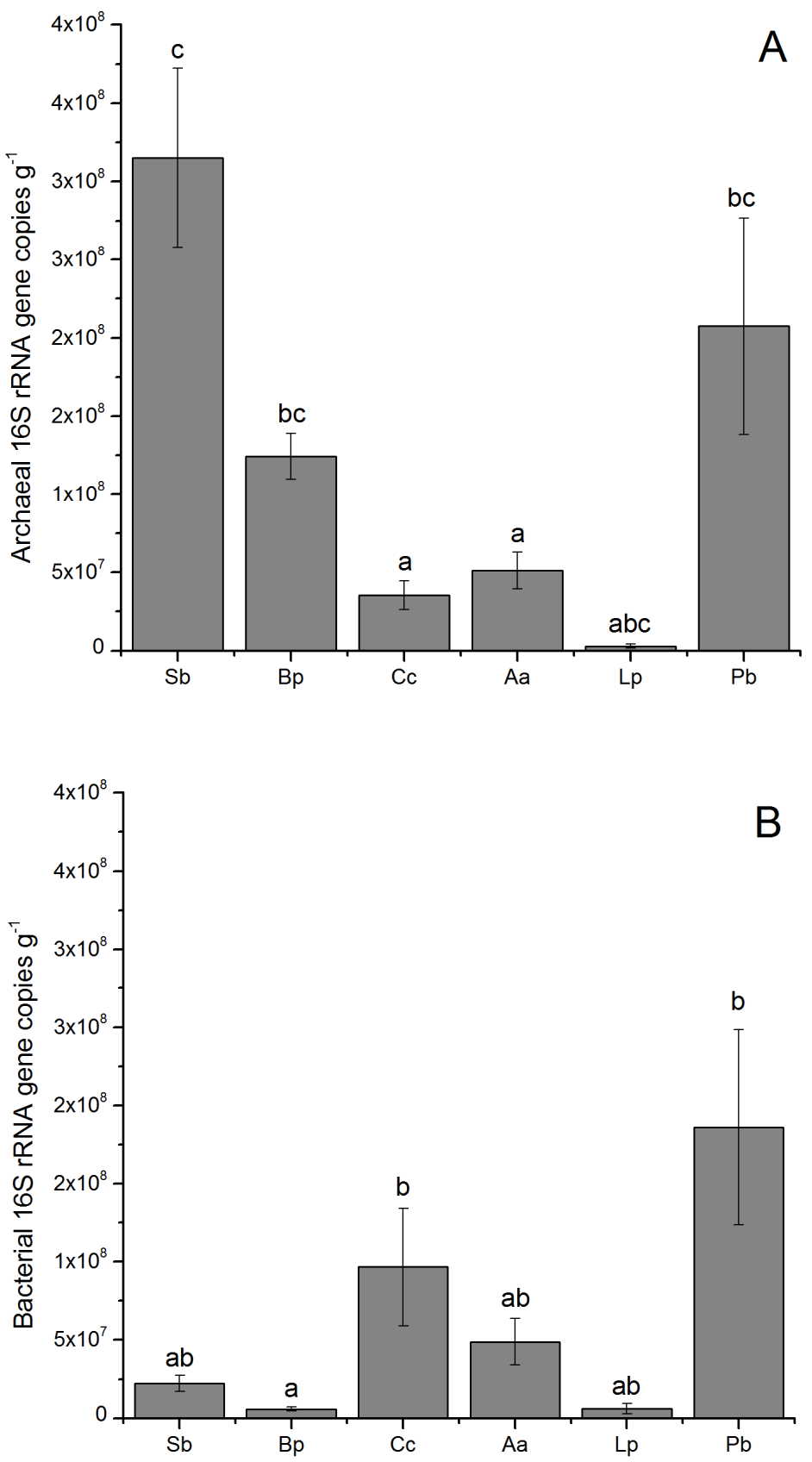


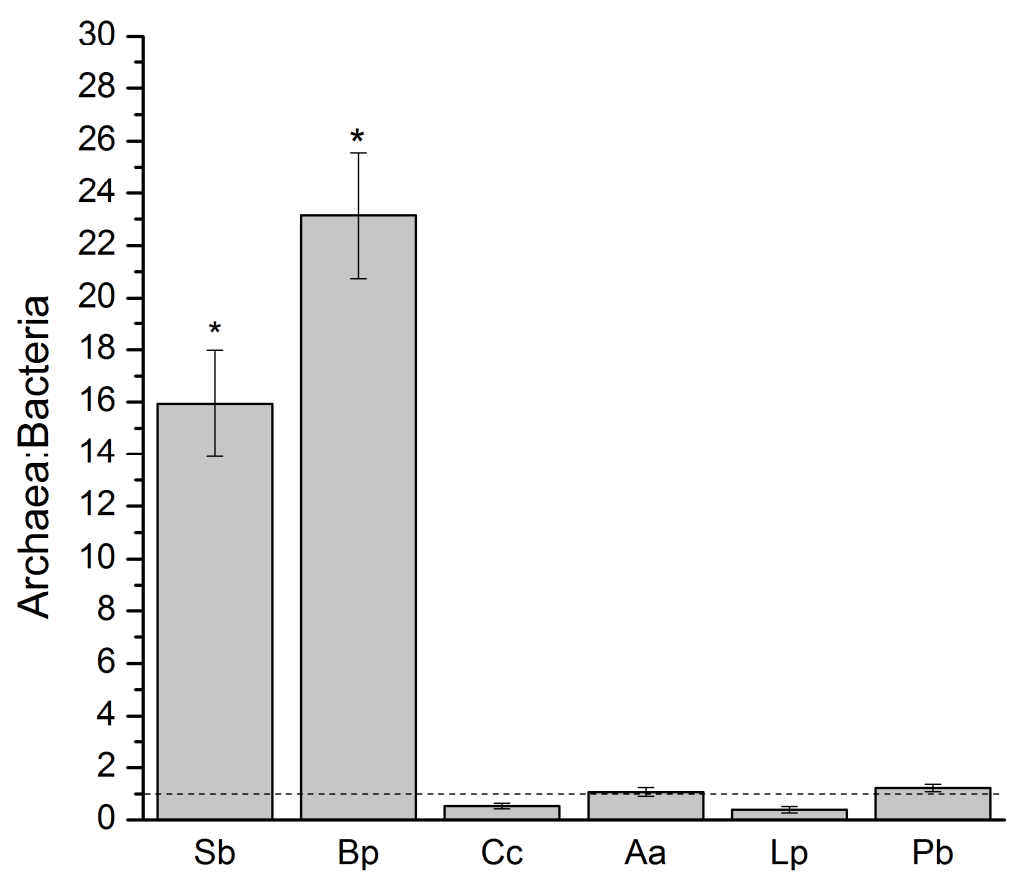

665 


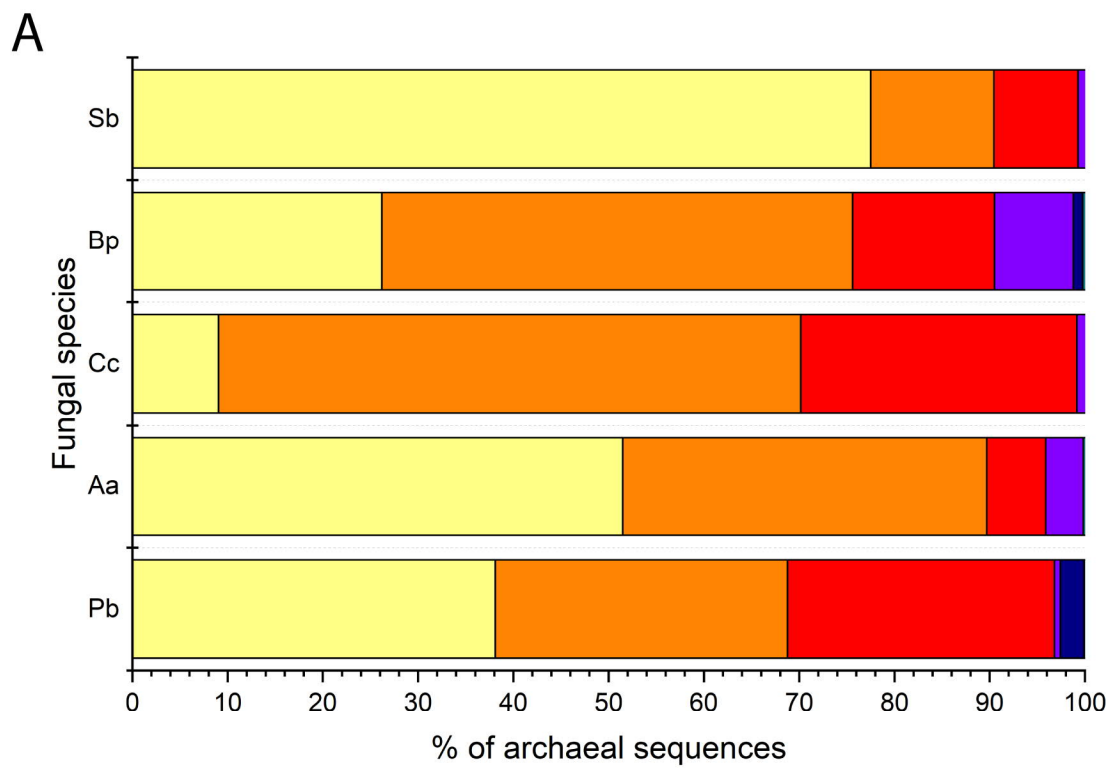

haumarchaeota, terrestrial grou inermoplasmata

narchaeotic Group

Thaumarchaeota class SC-EA05

B

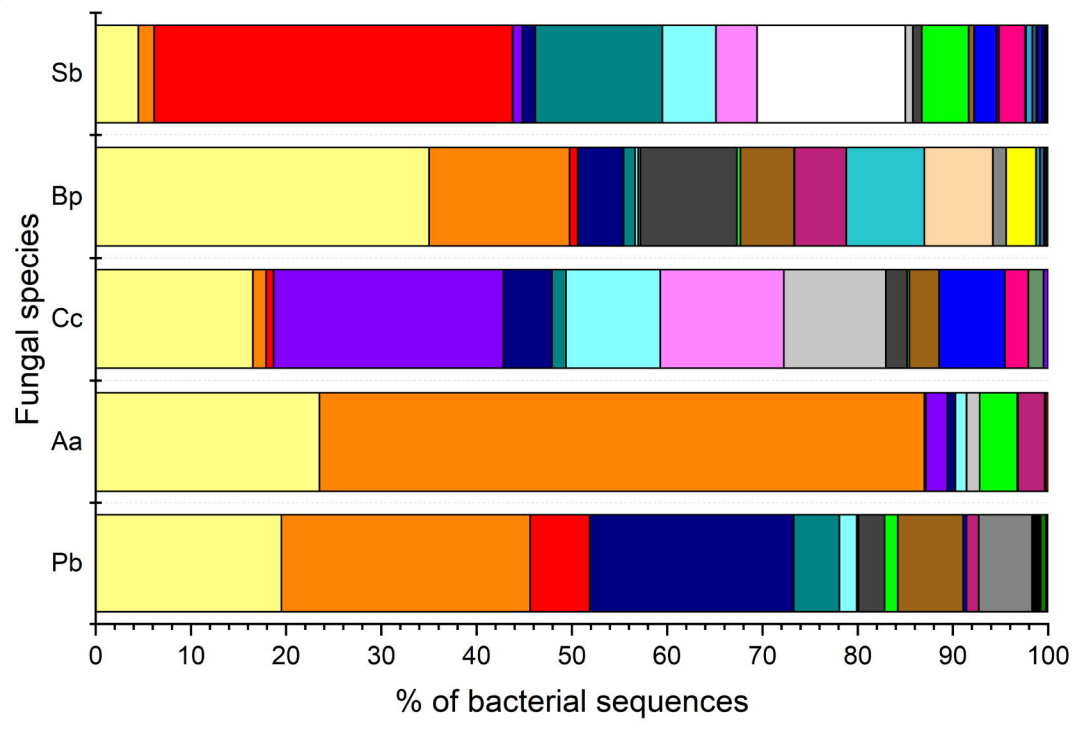

\begin{tabular}{|l|l|}
\hline Pseudomonadales \\
Bacillales \\
Enterobacteriales \\
Sphingobacteriales \\
Corynebacteriales \\
Clostridiales \\
Burkholderiales \\
Rhizobiales \\
Dehalococcoidia uncultured \\
Caulobacterales \\
Lactobacillales \\
Micrococcales \\
Flavobacteriales \\
Rhodosirillales \\
Neisseriales \\
Cyanobacteriales subsect. IV \\
Streptomycetales \\
Shingomonadales \\
Rhodobacterales \\
Pasteurellales \\
Acidobacteriales \\
Actinomycetales \\
Acidimicrobiales \\
Nitrosomonadales \\
Deinococcales \\
Alphaproteobacteria SAR clade \\
Rickettsiales \\
SBR clade \\
Cytophagales \\
Propionibacteriales \\
Anaerolineales \\
Frankiales
\end{tabular}




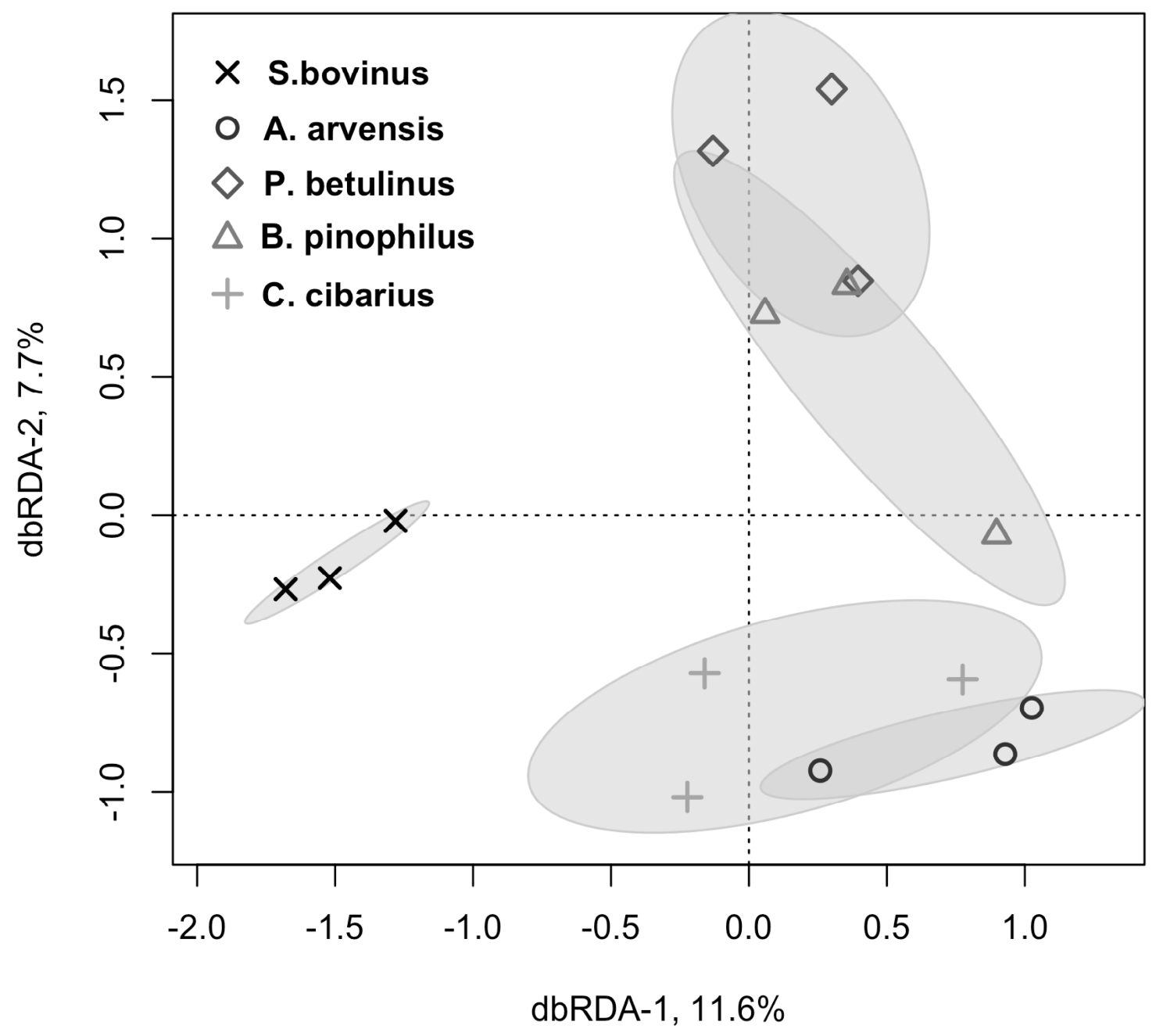

667 
668 Archaea are prominent members of the prokaryotic communities colonizing common forest

669 mushrooms

670

671 Rinta-Kanto JM, Pehkonen, K, Sinkko H, Tamminen MV, Timonen S

672

673

674 Supplementary information

675

676

677 Supplementary Table 1. Primers used for Illumina sequencing library preparation for sequencing of 678 archaeal 16S rRNA gene fragments.

679

680

Primer name

Sequence

681 miseq_A349_F1

ACACGACGCTCTTCCGATCTYRYRGYGCASCAGKCGM GAAW

682 miseq_uni_F2

AATGATACGGCGACCACCGAGATCTACACTCTTTCCCTACACGACGCTCTTCCGATCT

683 miseq_A539_R1

GGAGTTCAGACGTGTGCTCTTCCGATCTGCBGGTDTTACCGCGGCGGCTGRCA

684 miseq_uni_R2_bc001

CAAGCAGAAGACGGCATACGAGATTCCGTGCGCGTGACTGGAGTTCAGACGTGTGCTCTTCCGATCT

685 miseq_uni_R2_bc002

CAAGCAGAAGACGGCATACGAGATTGTTTCCCAGTGACTGGAGTTCAGACGTGTGCTCTTCCGATCT

686 miseq_uni_R2_bc003

CAAGCAGAAGACGGCATACGAGATGGTAATGAAGTGACTGGAGTTCAGACGTGTGCTCTTCCGATCT

687 miseq_uni_R2_bc004

CAAGCAGAAGACGGCATACGAGATGAAACTGGGGTGACTGGAGTTCAGACGTGTGCTCTTCCGATCT

688 miseq_uni_R2_bc005

CAAGCAGAAGACGGCATACGAGATACGGGCTGAGTGACTGGAGTTCAGACGTGTGCTCTTCCGATCT

689 miseq_uni_R2_bc006

CAAGCAGAAGACGGCATACGAGATATGAAGTATGTGACTGGAGTTCAGACGTGTGCTCTTCCGATCT

690 miseq_uni_R2_bc007

CAAGCAGAAGACGGCATACGAGATACTTATTGTGTGACTGGAGTTCAGACGTGTGCTCTTCCGATCT

691 miseq_uni_R2_bc008

CAAGCAGAAGACGGCATACGAGATGGCGGGAAAGTGACTGGAGTTCAGACGTGTGCTCTTCCGATCT

692 miseq_uni_R2_bc009

CAAGCAGAAGACGGCATACGAGATACACCTCGGGTGACTGGAGTTCAGACGTGTGCTCTTCCGATCT

693 miseq_uni_R2_bc010

CAAGCAGAAGACGGCATACGAGATCTCATTGGGGTGACTGGAGTTCAGACGTGTGCTCTTCCGATCT

694 miseq_uni_R2_bc011

CAAGCAGAAGACGGCATACGAGATGCTGCCGCGGTGACTGGAGTTCAGACGTGTGCTCTTCCGATCT

695 miseq_uni_R2_bc012

CAAGCAGAAGACGGCATACGAGATCGATGGTGTGTGACTGGAGTTCAGACGTGTGCTCTTCCGATCT

696 miseq_uni_R2_bc013

CAAGCAGAAGACGGCATACGAGATTCAAAGCTGGTGACTGGAGTTCAGACGTGTGCTCTTCCGATCT 
697 miseq_uni_R2_bc014

698 miseq_uni_R2_bc015

699 miseq_uni_R2_bc016

700 miseq_uni_R2_bc017

701 miseq_uni_R2_bc018

702 miseq_uni_R2_bc019

703 miseq_uni_R2_bc020

704 miseq_uni_R2_bc021

705 miseq_uni_R2_bc022

706 miseq_uni_R2_bc023

707 miseq_uni_R2_bc024

708 miseq_uni_R2_bc025

709 miseq_uni_R2_bc026

710 miseq_uni_R2_bc027

711 miseq_uni_R2_bc028

712 miseq_uni_R2_bc029

713 miseq_uni_R2_bc030
CAAGCAGAAGACGGCATACGAGATCAGCGGCATGTGACTGGAGTTCAGACGTGTGCTCTTCCGATCT CAAGCAGAAGACGGCATACGAGATCCGACAAATGTGACTGGAGTTCAGACGTGTGCTCTTCCGATCT CAAGCAGAAGACGGCATACGAGATTAAGGGAGAGTGACTGGAGTTCAGACGTGTGCTCTTCCGATCT CAAGCAGAAGACGGCATACGAGATTTGGGCGCGTGACTGGAGTTCAGACGTGTGCTCTTCCGATCT CAAGCAGAAGACGGCATACGAGATAGGTCGGTCGTGACTGGAGTTCAGACGTGTGCTCTTCCGATCT CAAGCAGAAGACGGCATACGAGATAATGTCAAGGTGACTGGAGTTCAGACGTGTGCTCTTCCGATCT CAAGCAGAAGACGGCATACGAGATGTTCGCAGGGTGACTGGAGTTCAGACGTGTGCTCTTCCGATCT CAAGCAGAAGACGGCATACGAGATTATCAATCTGTGACTGGAGTTCAGACGTGTGCTCTTCCGATCT CAAGCAGAAGACGGCATACGAGATGTCTAACGCGTGACTGGAGTTCAGACGTGTGCTCTTCCGATCT CAAGCAGAAGACGGCATACGAGATTTACTATACGTGACTGGAGTTCAGACGTGTGCTCTTCCGATCT CAAGCAGAAGACGGCATACGAGATTGCACCCGTGTGACTGGAGTTCAGACGTGTGCTCTTCCGATCT CAAGCAGAAGACGGCATACGAGATTGGGACCTCGTGACTGGAGTTCAGACGTGTGCTCTTCCGATCT CAAGCAGAAGACGGCATACGAGATGAGTITGATGTGACTGGAGTTCAGACGTGTGCTCTTCCGATCT CAAGCAGAAGACGGCATACGAGATAACAGTATTGTGACTGGAGTTCAGACGTGTGCTCTTCCGATCT CAAGCAGAAGACGGCATACGAGATATCGCACCAGTGACTGGAGTTCAGACGTGTGCTCTTCCGATCT CAAGCAGAAGACGGCATACGAGATCTAGAATCTGTGACTGGAGTTCAGACGTGTGCTCTTCCGATCT CAAGCAGAAGACGGCATACGAGATCGCCAAGGGGTGACTGGAGTTCAGACGTGTGCTCTTCCGATCT

714

715 Supplementary Table 2. Regression analysis for the square root-transformed ratio of the mean of 716 archaeal to bacterial rRNA gene copies in different fungal species $(n=6$, except L. perlatum $n=3)$. In 717 the results, estimate for intercept $=$ mean of L. perlatum (reference group).

718

\begin{tabular}{lllll}
\hline & Estimate & Std. Error & t value & $\operatorname{Pr}(>|\mathbf{t}|)$ \\
\hline (Intercept) & 0.6109 & 0.2256 & 2.708 & 0.0116 \\
A. arvensis & 0.4057 & 0.2763 & 1.468 & 0.1536 \\
B. pinophilus & 4.1687 & 0.2763 & 15.088 & $1.12 \mathrm{E}-14$ \\
C. cibarius & 0.0989 & 0.2763 & 0.358 & 0.7232 \\
P. betulinus & 0.4885 & 0.2763 & 1.768 & 0.0883 \\
S. bovinus & 3.3445 & 0.2763 & 12.104 & $2.03 \mathrm{E}-12$ \\
\hline
\end{tabular}

719 

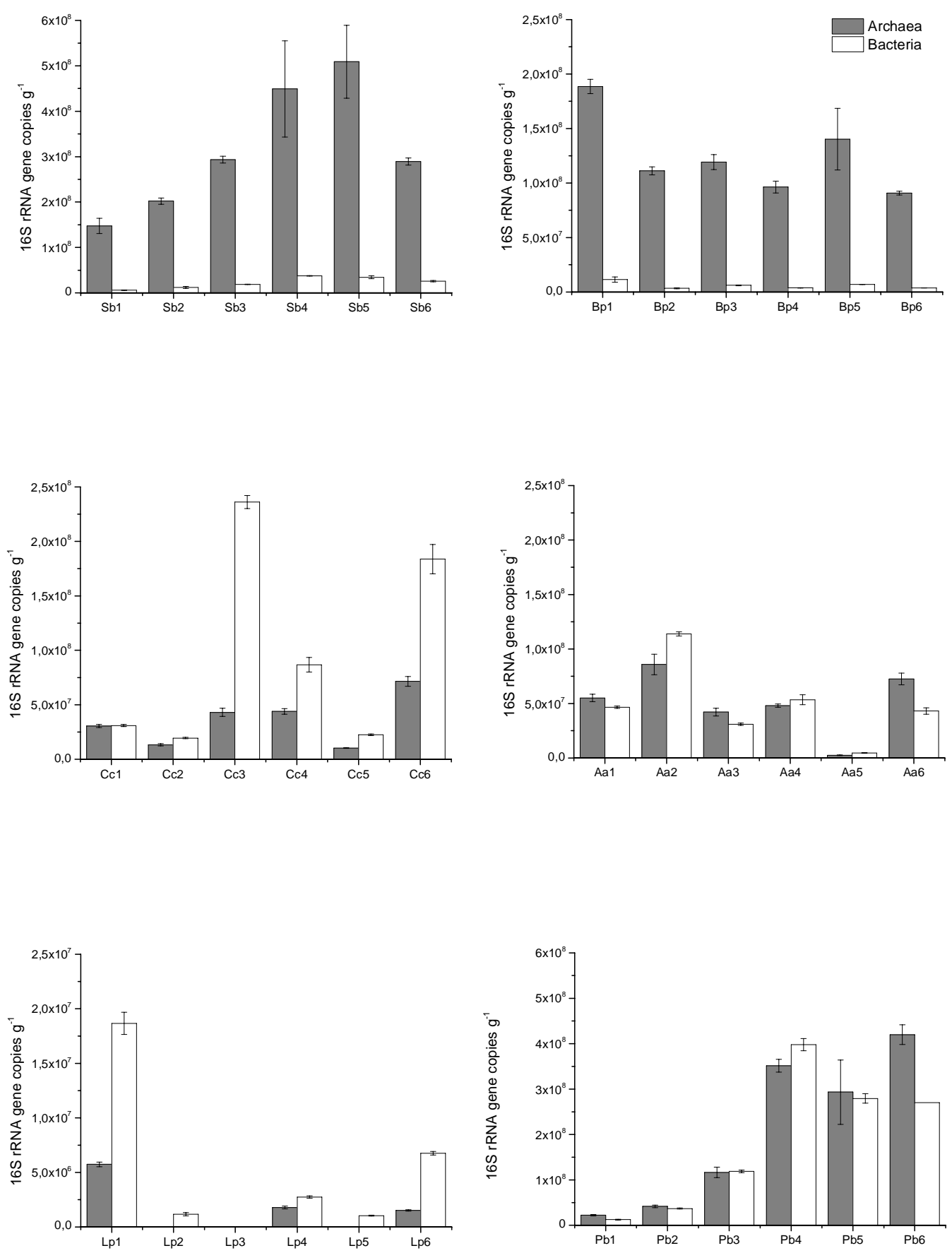

722 Supplementary Figure 1. Abundances of archaeal and bacterial 16S rRNA gene copies in biological 723 replicates of fungal specimens included in this study. Labels on the $\mathrm{x}$-axes correspond to the initial 724 letters of the fungal species names and the number (1-6) identifies the biological replicate. 